\section{Time to rethink EMRs}

With use of EMRs in Canada at an alltime high, ${ }^{1}$ evidence showing that they improve medical outcomes is very thin at best. We should be practising evidence-based medicine, so why are the provincial and national medical organizations continuing to push EMRs?

EMRs also deteriorate the physician-patient relationship. They are a distraction, and physicians may spend more time looking at their computer screens than at their patients.

EMRs are expensive, time-consuming and complex to set up and maintain. The US, which has the most computerized medical system in the world, also has the most expensive medical system and far worse medical outcomes than most other industrialized nations. ${ }^{2}$

We should learn from our neighbour and focus our resources where they will have the biggest impact. I urge physicians who feel likewise to share these concerns with their local and national politicians and medical associations.

\section{Thomas Hall MD}

Memorial University of Newfoundland, St. John's, NL

\section{References}

1. Collier R. National Physician Survey: EMR use at 75\%. CMAJ 2015; 187:E17-8.

2. Health at a Glance 2013: OECD indicators. Paris: Organisation for Economic Co-operation and Development; 2013.

CMAJ 2015. DOI:10.1503/cmaj.1150033

\section{Cannabis every day?}

In their article on cannabinoid hyperemesis syndrome (CHS), ${ }^{1}$ King and Holmes state that the syndrome occurs "in patients who have been using cannabis daily for years," and that "patients with CHS have a history of daily use of natural or synthetic cannabis." This implies that daily cannabis use is a prerequisite for $\mathrm{CHS}$.

According to Simonetto and colleagues, ${ }^{2} 59 \%$ of individuals with CHS report daily use of cannabis, with $25 \%$ using it no more than three times weekly, and some using it once a week.

Daily use of cannabis is not required for the development of CHS and, when clinically appropriate, should remain a diagnostic consideration even in relatively infrequent cannabis users.

\section{Steven L. Shumak MD}

Division of General Internal Medicine, University of Toronto, Toronto, Ont.

\section{References}

1. King C, Holmes A. Cannabinoid hyperemesis syndrome. CMAJ 2015;187:355.

2. Simonetto DA, Oxentenko AM, Herman ML, et al. Cannabinoid hyperemesis: a case series of 98 patients. Mayo Clin Proc 2012;87:114-9.

CMAJ 2015. DOI:10.1503/cmaj.1150034

\section{Inguinal hernia}

Summarizing advice from Choosing Wisely Canada on minimally symptomatic inguinal hernias in adults, Bohnen re-emphasizes that management may include "watchful waiting for up to two years." Bohnen cites a randomized trial ${ }^{2}$ that reported a control group of 364 patients with hernia followed without intervention for two years. These investigators now report the long-term results of their trial, ${ }^{3}$ and although the majority of those on long-term follow-up elected to have surgery, the researchers still counsel that watchful waiting for up to 11.5 years is a reasonable and safe strategy. Other Canadian surgeons have also acknowledged that watchful waiting without a time limit is an appropriate strategy for asymptomatic groin hernias. ${ }^{4}$

The author presents estimates of the death rate from elective surgery for inguinal hernia $(0.2 \%$, range $0.0 \%-1.8 \%)$ and the death rate from emergency intervention for incarceration/strangulation (4\%) but fails to emphasize that the yearly rate of irreducibility associated with a nonoperative approach in such trials is only $0.4 \% .^{5}$ This means that if 1000 people with a small, minimally symptomatic hernia have elective surgery, 2 , or maybe as many as 18 , will die from complications. If 1000 such people elect for watchful waiting, 4 will experience an irreducible hernia per year, or 40 after 10 years. Of the 40 experiencing irreducibility, $4 \%$ are at risk of dying from emergency surgery, or 1.6 per 1000 people per 10 years. Looks like a distinct advantage for watchful waiting if death from intervention is your main worry.

Also, Bohnen's summary discusses a 55-year-old man: he fails to consider that mortality and complications may increase in seniors.

\section{R.M. Preshaw MD}

Vancouver Island, BC

\section{References}

1. Bohnen JMA. Inguinal hernia in a 55-year-old man. CMAJ 2014;186:1010-1.

2. Fitzgibbons RJ Jr, Giobbie-Hurder A, Gibbs JO, et al. Watchful waiting vs repair of inguinal hernia in minimally symptomatic men: a randomized clinical trial. JAMA 2006:295:285-92.

3. Fitzgibbons RJ Jr, Ramanan B, Arya S, et al. Longterm results of a randomized controlled trial of a nonoperative strategy (watchful waiting) for men with minimally symptomatic inguinal hernias. Ann Surg 2013;258:508-15.

4. Van den Heuvel, B, Dwars, BJ, Klassen DR, et al. Is surgical repair of an asymptomatic groin hernia appropriate? A review. Hernia 2011;15:251-9.

5. INCA Trialists Collaboration. Operation compared with watchful waiting in elderly male hernia patients: a review and data analysis. $\mathrm{J} \mathrm{Am} \mathrm{Coll}$ Surg 2011; 212:251-9.

CMAJ 2015. DOI:10.1503/cmaj.1150035

\section{The author responds}

The argument that minimally symptomatic hernias may be left unoperated upon is well supported by data described by Preshaw ${ }^{1}$ and cited in my article, ${ }^{2}$ that show irreducibility rates associated with a nonoperative approach and focus on patients with asymptomatic and mildly symptomatic inguinal hernias.

The patient described in my article ${ }^{2}$ had a painful hernia that was felt during sporting activities and affected his work.

There is a paucity of information on hernia-related risks in untreated patients with symptomatic inguinal hernias, because symptomatic patients usually have operations. In countries where that is not the case, a substantial burden of disease exists because of morbidities and deaths attributed to hernias.

Most often, surgery is indicated for an otherwise suitable patient who 